\title{
Functional Restoration of a Midforearm Level Amputation using the Second Toe Transfer
}

\author{
Mohit Sharma ${ }^{1}$ Shravan Rai K. S. ${ }^{1}$ Srilekha Reddy G. ${ }^{1}$ Shruti Kongara ${ }^{1}$ \\ ${ }^{1}$ Department of Plastic and Reconstructive Surgery, Amrita Institute \\ of Medical Sciences, Kochi, India \\ Address for correspondence Shravan Rai K. S. MBBS, MS, \\ Samvedana, \#415, 3rd Cross, 3rd Main, H M T Layout, Anandnagar, \\ Bangalore-560024, India (e-mail: raishravan89@gmail.com).
}

Indian J Plast Surg 2021;54:367-369.

\begin{abstract}
Keywords

- forearm amputation

- toe transfer

- Vilkki procedure

Unilateral midforearm level amputation is a severely debilitating situation. The present solution for this problem is either restoration of function using a prosthetic hand, or a vascularized composite allotransplant (VCA) in some very selected cases. In cases of distal forearm level amputations, even vascularized second toe transfer could be done on the radial side of the hand to achieve good functional restoration. We present a case of midforearm level amputation in which the second toe transfer has been done above the level of insertion of pronator teres muscle to achieve meaningful function. This report highlights the fact that a single toe transfer could be helpful in achieving meaningful prehension, even at this proximal.
\end{abstract}

\section{Introduction}

When it comes to functional restoration in a forearm amputee, the number of options available are limited. Considering that a more drastic option such as a composite allotransplant is associated with several complications, there has to be some reliable method to restore functionality in patients who are not interested in prosthetic rehabilitation. Single or multiple vascularized toe transfers for pinch restoration to regain useful function is a more realistic treatment option for such patients. ${ }^{1}$

\section{Case Report}

This is a case of a 24-year-old old patient who underwent a right midforearm amputation in 2013 due to a train accident. $\mathrm{He}$ is an aspiring dialysis technician. He attempted using a myoelectric prosthesis following the accident to carry out his routine activities and to assist with his occupation in the dialysis unit, but experienced discomfort and pain following prolonged use of the prosthesis, and one of the major limitations was inability to handle activities involving the use of water (-Fig. 1).

He presented to the outpatient department, enquiring about viable options to restore function in his amputated right upper limb, so as to avoid using the prosthetic device.

The patient was examined and clinically evaluated. His disabilities of the arm, shoulder and hand (DASH) score at presentation was 38.33/100. An MRI scan was also taken preoperatively to evaluate the residual forearm musculature.
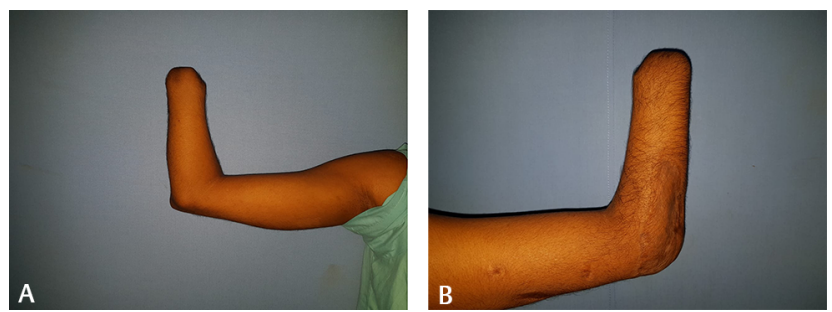

Fig. 1 Right upper limb anterior view (preoperative image). published online

September 17, 2021
DOI https://doi.org/

10.1055/s-0041-1735718 ISSN 0970-0358 (c) 2021. Association of Plastic Surgeons of India.

This is an open access article published by Thieme under the terms of the Creative Commons Attribution-NonDerivative-NonCommercial-License, permitting copying and reproduction so long as the original work is given appropriate credit. Contents may not be used for commercial purposes, or adapted, remixed, transformed or built upon. (https://creativecommons.org/licenses/by-nc-nd/4.0/). Thieme Medical and Scientific Publishers Pvt. Ltd. A-12, 2nd Floor, Sector 2, Noida-201301 UP, India 
After careful evaluation, he was given the option of a second toe vascularized transfer onto the radial border of the remnant forearm to restore pinch. ${ }^{2,3}$ The limitations and associated complications were explained. Informed consent was taken and the patient was taken up for the procedure.

The second toe of the right foot was harvested, which was fixed approximately $5 \mathrm{~cm}$ proximal to the end of the amputation stump on a wedge cut out of the radius at an angle of approximately 20 degrees; fixation was done by three $1.2 \mathrm{~mm}$ diameter $\mathrm{k}$ wires transfixing the toe metatarsal bone on to the radius. The toe was revascularized via anastomosis to the radial artery and cephalic vein end to end using 9/0 nylon. Flexor action was restored by connecting the forearm flexor carpi radialis to the toe flexor digitorum brevis and the forearm flexor digitorum superficialis to the toe flexor digitorum longus. Extensor action was similarly restored by connecting the forearm extensor carpi radialis longus to the extensor digitorum brevis of the toe and the brachioradialis to the extensor digitorum longus. Both extensor and flexor tendons were fixed in such a way that the transferred toe stays in the neutral position (midway between full extension and full flexion). The most important factor is to ensure adequate contact between the thumb and the distal stump, in order to ensure adequate pinch strength (-Figs. 2 and $\mathbf{3}$ ).

The superficial sensory branch of the radial nerve was anastomosed to the deep peroneal nerve, and the cut end of
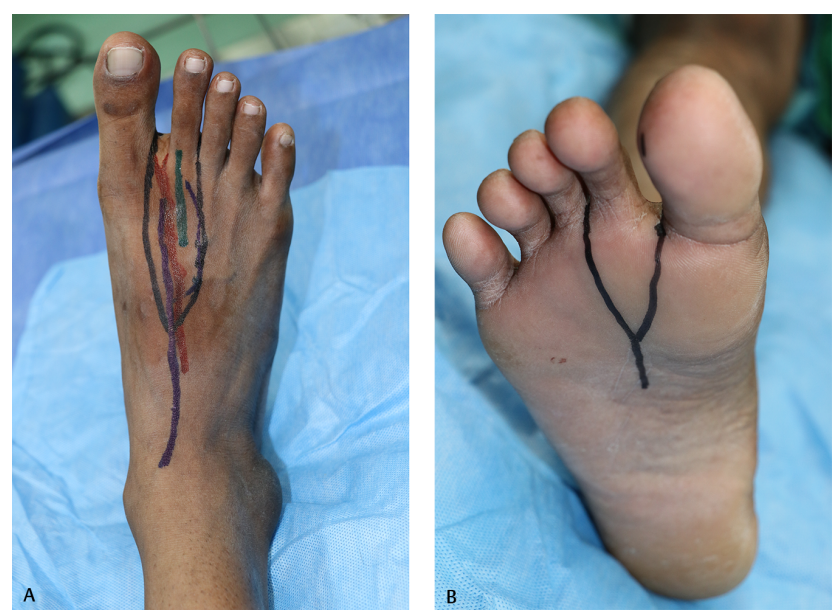

Fig. 2 (A) Dorsal view of right foot for 2 nd toe harvest. (B) Plantar view of right foot for second toe harvest.

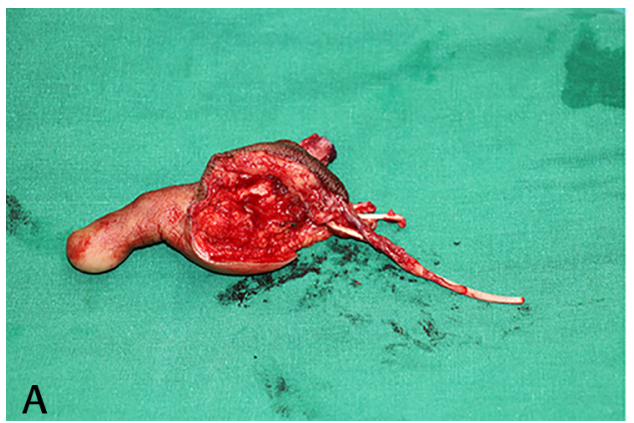

the median nerve was anastomosed to both the planter digital nerves using 10/0 nylon. No slap was placed postoperatively.

The only complication encountered was necrosis of the skin edges on the donor site wound, which healed by secondary intention with conservative management.

Rehabilitation of the operated hand was started by the second week. At 4 months follow-up, he could perform activities like opening a bottle, grasping and lifting smaller objects pertaining to his daily life requirements. He gained protective pain and temperature sensation and stereognosis for small objects, with a two point discrimination of $6 \mathrm{~mm}$ at the tip.

His DASH score at 1-year follow-up is 19.64/100, which is significant improvement (-Figs. 4-6; - Video 1; Supplementary - Fig. S1 [available online only]).

\section{Video 1}

Showing postoperative function. Online content including video sequences viewable at: https:// www.thieme-connect.com/products/ejournals/ html/10.1055/s-0041-1735718.

\section{Discussion}

The number of reconstructive options for forearm amputees to restore functionality are limited. Earlier when microsurgical reconstruction was not an option, the Krukenberg procedure could have been considered, which helps to create a forceps-like action using the two forearm bones. ${ }^{4}$ In 1983 , Vilkki reported a good alternate option to the Krukenberg operation, in which a second toe was transferred for restoring
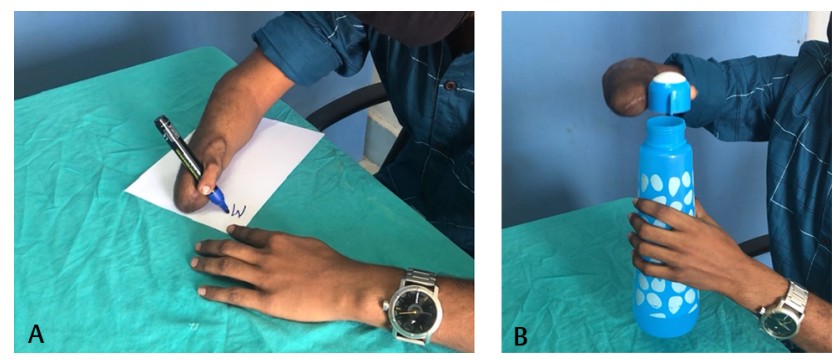

Fig. 4 (A) 1-year postoperative image of patient writing. (B) 1-year postoperative image of patient opening a bottle.

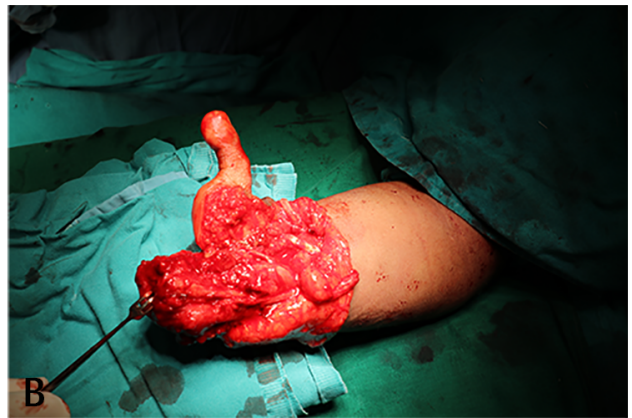

Fig. 3 (A) Harvested second toe. (B) Right upper limb intraoperative image after second toe fixation. 


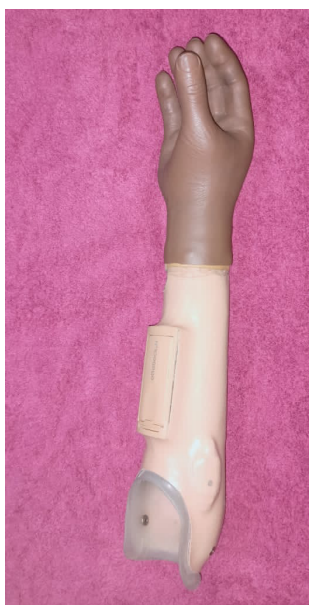

Fig. 5 Prosthesis used by the patient.

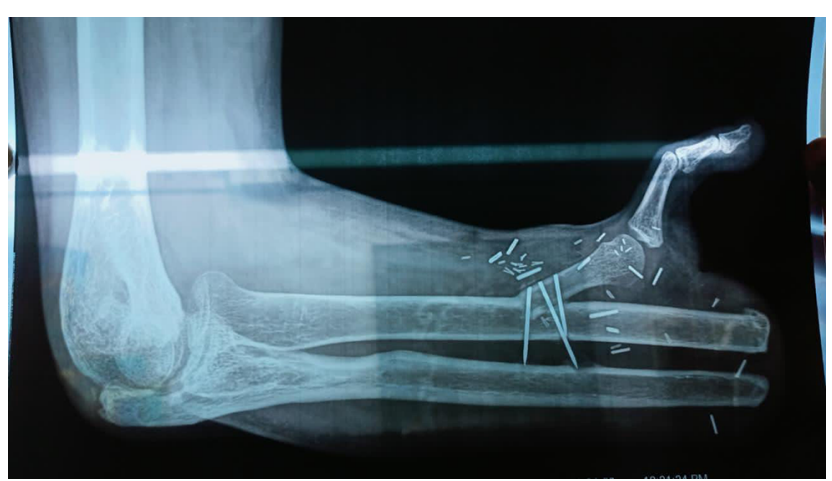

Fig. 6 Postoperative X-Ray.

the function in hand amputees. ${ }^{5}$ Around 20 years later, a case series studying the long-term results of Vilkki's technique, where toe to antebrachial stump transfer was performed in 12 patients, were studied. ${ }^{6}$ This study only included patients with wrist level or distal forearm amputation. Similar procedures have been reported in other cases of amputation, which were also at the distal level. ${ }^{7}$ The paper stated that a good functional outcome could not be expected in a shorter forearm stump; hence, midforearm amputees were not included in their series.

Since last two decades, the option of vascularized composite allotransplantation has become available, which is associated with its own set of issues. ${ }^{89}$ The risks associated with transplant may outweigh the benefits, especially in a unilateral amputee, and it should be used in unilateral amputations only if the patient is unable to adjust to body image distortion and restricted functionality following the loss of a dominant limb.

The patient clearly did not want to use the myoelectric prosthesis nor was he willing to undertake the risks associated with transplantation; therefore, after very careful study of the MRI images, we decided to offer him second toe transfer for providing a pinch grip and some capability for grasping smaller-sized objects.

Our patient achieved significant improvement in function after the procedure. This paper stresses the fact even midfoream amputees, who have been traditionally left out from the possible consideration for second toe transfer for functional restoration, could benefit from this procedure.

\section{Conclusion}

To the best of our knowledge, at a level above the insertion of pronator teres, the procedure of second toe transfer has never been reported in the literature. Even in a midforearm amputee, it seems to be a viable surgical option for, at least, partial restoration of prehensile functional, if the evaluation shows presence of enough muscle length to motorize the second toe and especially if the patient chooses not to go for prosthetic rehabilitation.

This modality of treatment should be considered in select category of patients, who are not candidates for vascularized composite allotransplant (VCA) or prosthetic rehabilitation.

\section{Conflict of Interest}

None.

\section{References}

1 Dominique $\mathrm{M}$, Katarina $\mathrm{W}$. The Vilkki Procedure as an emergency treatment in an apocalyptic hand injury-a case report and first description. Case Reports Plast Surg Hand Surg 2017;4(1):96-98

2 Vilkki SK, Toe to antebrachial stump transplantation. Functional results after new grip reconstruction. In: Brunelli G, ed. Textbook of Microsurgery Masson; 1988:329-333

3 Vilkki SK, Grip reconstruction with toe to antebrachial stump transfer. In: Landi A, ed. Reconstruction of the Thumb London; 1989 233-241

4 Kallio KE. Recent advance in Krukenberg's operation. Acta Chir Scand 1948;97:165-188

5 Vilkki SK. [Free toe transfer to the forearm stump following wrist amputation-a current alternative to the Krukenberg operation]. Handchir Mikrochir Plast Chir 1985;17(2):92-97

6 Vilkki SK, Kotkansalo T. Present technique and long-term results of toe-to-antebrachial stump transplantation. J Plast Reconstr Aesthet Surg 2007;60(7):835-848

7 Borovikov A. Toe-to-hand transfers in the rehabilitation of frostbite injury. Ann Plast Surg 1993;31(3):245-250

8 Hettiaratchy S, Butler PE, Lee WP. Lessons from hand transplantations. Lancet 2001;357(9255):494-495

9 Michael E, Neil HM, Alastair P. History and ethics of hand transplants. J R Soc Med Sh Rep 2012;3(10):74 